\title{
Factors Associated with the Use of Modern Contraceptive Methods by Women of Childbearing Age in Parakou in 2017
}

\author{
K. Salifou1, R. Sidi Imorou', M. Vodouhe'1, M. E. Gounon'1, F. Hounkponou' ${ }^{1}$ A. Obossou ${ }^{1}$, \\ C. Koukoui1, R. X. E. Perrin², E. Alihonou² \\ ${ }^{1}$ UFR of Gynecology and Obstetrics, Faculty of Medicine, University of Parakou, Parakou, Benin \\ ${ }^{2}$ UFR of Gynecology and Obstetrics, Faculty of Health Sciences, University of Abomey-Calavi, Cotonou, Benin \\ Email: salifoukabibou@yahoo.com
}

How to cite this paper: Salifou, K., Sidi Imorou, R., Vodouhe, M., Gounon, M.E., Hounkponou, F., Obossou, A., Koukoui, C., Perrin, R.X.E. and Alihonou, E. (2018) Factors Associated with the Use of Modern Contraceptive Methods by Women of Childbearing Age in Parakou in 2017. Open Journal of Obstetrics and Gynecology, 8, 521-530.

https://doi.org/10.4236/ojog.2018.85059

Received: April 11, 2018

Accepted: May 18, 2018

Published: May 21, 2018

Copyright $\odot 2018$ by authors and Scientific Research Publishing Inc. This work is licensed under the Creative Commons Attribution International License (CC BY 4.0).

http://creativecommons.org/licenses/by/4.0/

\begin{abstract}
As in other countries of West Africa, Benin has a low rate of MCM utilization. The factors which lead to this low rate of use vary from one country to another. Purpose: The purpose of this work was to determine the factors associated with the use of modern contraceptive method (MCM) by women of childbearing age (WCBA) in Parakou in 2017. Materials and Methods: It was a cross-sectional and descriptive study with an analytical purpose among WCBA selected in households of the municipality of Parakou after a 2-degree cluster survey. Results: The WCBA's average age was $29 \pm 5.6$ years old with extremes of 15 and 46 years. The modern contraceptive prevalence was $14.74 \%$. Among WCBA, $57.14 \%$ had an average level of knowledge. The media were the main source of information (75.84\%). Among them $34.39 \%$ never discussed the matter with their spouse; the latter were not in favor of contraception. The educational level, the perception of woman, the spouse's favorable opinion, the discussion with the spouse, the level of knowledge of MCM and the knowledge of the existence of FP service were significantly associated with the use of MCM with $p=0.0000$ after multivariate analysis. Conclusion: The level of MCM use still remains low. Any effort to increase the modern contraceptive prevalence should take into account its associated factors in order to optimize the use of MCM in the municipality of Parakou in 2017.
\end{abstract}

\section{Keywords}

Methods, Modern Contraception, Use, Factors Associated, Women of Childbearing Age, Parakou

\section{Introduction}

Benin is characterized by a high maternal and infant/child mortality but also a 
high birth rate with a composite fertility index (CFI) of 4.9 children per woman [1]. Its economic fabric still embryonic does not make it possible to meet the basic needs of populations [1]. Effectively used, it is proven that contraception can not only contribute to reduce maternal mortality but it can also limit the high growth rate of population in Africa and thus promote development [2] [3] [4]. But in spite of these proven advantages for communities, it was found that only 9\% of women of childbearing age (WCBA) used a modern contraceptive method (MCM) according to the results of Benin Demographic and Health Survey (BDHS-VI) in 2012 [1]. The factors limiting its use are not identified yet. So, this study's purpose is to determine the factors associated with the use of modern contraceptive methods by women of childbearing age in Parakou in 2017.

\section{Materials and Methods}

\subsection{Type of Study and Collection Period}

It was a cross-sectional and descriptive study with an analytical purpose and prospective data collection which was carried out over a three-month (3) period from April $1^{\text {st }}$ to June $30^{\text {th }} 2017$.

\subsection{Target Population}

It consisted of all the WCBA of the municipality of Parakou in 2017.

\subsubsection{Inclusion Criteria}

Were involved in our study, WCBA (15 to 49 years old) who resided permanently in Parakou for at least 6 months and who gave their free and informed consent.

\subsubsection{Exclusion Criteria}

Were not involved in our study, people with mental illnesses, pregnant women, women in early menopause, women who could not have children (bilateral salpingectomy, uterine agenesis, uterine malformation, hemostasis hysterectomy).

\subsection{Sampling}

\subsubsection{Sample Size}

The sample size is obtained using Schwartz formula: $N=k Z \alpha^{2} p(1-p) / I^{2}$.

With a $14 \%$ contraceptive prevalence in Benin (BDHS-IV); a p-value $(\alpha)$ of 0.05 that is to say $Z \alpha=1.96$; a desired accuracy $(i)$ of $3 \%$ and a cluster effect $(k)$ of 2.

$N=(1.96)^{2} \times 0.14 \times 0.86 \times 2 /(0.03)^{2}=1027.8414222 \approx 1028$ subjects.

This size was increased by $10 \%$ to take account of non-respondents and possible poorly completed forms.

\subsubsection{Sampling Technique}

The study was conducted according to a 2-degree cluster effect survey technique. The sampling frame was composed of the list of 106 neighborhoods and sub-neighborhoods in the municipality of Parakou with their respective target 
populations. We chose to take 30 clusters, as suggested by WHO. The size of each cluster was $37.7 \approx 38(1131 / 30)$ individuals.

The selection of the thirty clusters was made as follows:

1) The realization of the table of the cumulative target population (the cumulative total population is 49,743 ).

2) The determination of the cluster step. It was obtained by dividing the cumulative total population by 30 (the cluster step obtained is 1658).

3) Determination of the beginning (d): We drew a number between 1 and the cluster step thanks to the software epi table (the number pulled is $\mathrm{d}=100$ ).

4) This number allowed us to determine the first cluster.

5) The second cluster was obtained by adding to number (d) the step of cluster.

\section{Draw of concessions:}

In each cluster drawn, the interviewer placed himself in the center of the district and drew lots of direction (either by the method of bottle or turned pen). In this direction, the investigator had entered a concession on two starting with his right with each new result we added the step of cluster until we get the 30 clusters.

Selection of households by concession and subject to survey by household:

1) Within the selected concessions, the households were in turn numbered and half of the households were randomly drawn.

2) In each selected household, a subject was drawn from the list of eligible subjects present in the household when the collection team passed.

3 ) If the number required for the cluster was not obtained in this direction, the investigator returned to the center of the district to choose another direction with the same method.

\subsection{Variables}

\subsubsection{Dependent Variables}

The dependent variable was the use of MCM. It is a modality qualitative binary variable (Yes/No). By MCM, we referred to the following methods: femidon, condom, pill, injectable, implant, intrauterine device (IUD), spermicide, tubal sterilization, vasectomy because they were the only ones to be mentioned by the WCBA.

\subsubsection{Independent Variables}

We considered the following factors predictive of the use of MCM: age, place of residence, ethnic group, religion, socio-professional group, educational level, socio-economic level, marital status, household type, parity, gestity, level of knowledge, perception of WCBA, spouse's opinion, discussion with the spouse and the knowledge of the existence of FP services.

The assessment criteria of the WCBA's level of knowledge was inspired from the model of Essi et al. [5]. So, 4 levels of knowledge were defined: poor, insuffi- 
cient, average and good.

1) $<25 \%$ of right answers $=$ Poor.

2) $[25 \%-50 \%$ [of right answers = Insufficient.

3) $[50 \%-70 \%$ [of right answers $=$ Average.

4) $\geq 70 \%$ of right answers $=$ Good.

\subsection{Data Collection Tools}

Data were collected during a personal interview on the basis of a prepared questionnaire administered to all the women involved in the survey.

Data collection procedure:

1) Interviewer training: There were six (06) interviewers with good knowledge of the local language trained by ABPF to raise awareness about FP.

2) A pre-test was done in an unsuccessful neighborhood.

3) The investigation phase itself: it had been spread over a period of three months (01 April to 30 June 2017).

\subsection{Data Processing and Analysis}

The data collected were stored with EPI Data 3.1 software. Bivariate analysis was carried out by means of Epi Info 7.1 software. Multivariate analysis was performed by means of SPSS version 2.0 software. Microsoft Excel 2016 helped to organize the data in tabular and graphic forms. Quantitative variables were expressed in the form of averages with their standard deviation. When intersecting two qualitative variables or comparing two percentages, Chi-square test (or Fisher exact test according to the case) and p-value had been used. We admit that there is a statistically significant association between two variables for any probability below $5 \%$.Prevalence ratio (PR) and Odds ratio (OR) were presented with their Confidence Intervals (CI). Logistic regression was used to identify factors which were associated with the use of MCM. Outputs for logistic regression were presented as Odds Ratio (OR) and confidence intervals (CI). CI not crossing one was assumed to be significant.

\section{Results}

In total, we surveyed 1140 WCBA. The WCBA's average age was $29 \pm 5.6$ years. The major part of the women were Beninese (99.04\%) and resided in an urban area (80\%). Most of them belonged to the Bariba ethnic group (33.33\%) and Fon related ethnic group $(27.11 \%)$ practicing Islam (56\%). The women surveyed were mostly traders/retailers $(30 \%)$. They were not educated $(25.35 \%)$ or had primary school level (32.81\%) and an average socioeconomic level (52.02\%). They were married in $58.68 \%$ of cases and lived in a monogamous household for most of them (47.54\%). The number of pregnancies ranged from 0 to 11 with an average of $3 \pm 1.9$. The WCBA surveyed were mainly pauciparous $(38.07 \%)$ and multiparous (24.3\%).

They used modern contraceptive methods in $14.74 \%$ of cases and injectable 
contraceptives were mostly used (Table 1). The main reasons for the non-use of MCM by the WCBA surveyed in the municipality of Parakou were side effects (47.07\%), the spouse's unfavorable opinion $(25.61 \%$, the desire to have a child (22.11\%) and the ignorance of MCM (12.96\%).

More than half of the women surveyed had an average level of knowledge. The main sources of information were the media (75.84\%) and parents/friends (74.63\%) (Table 2). The most known advantage was to avoid unwanted pregnancies $(98.09 \%)$ by these WCBA. The most identified side effects were metrorrhagia (76.21\%), obesity (70.77\%) and amenorrhea (55.56\%). Half of the women surveyed perceived MCM as a bad thing because of religious considerations. We find that $25.88 \%$ of the women surveyed had asserted that their spouses were not in favor of contraception and they never discussed this matter with them.So, they almost always comply with their opinions.

The educational level; OR 6.4; IC [3.52 -.11.63], $P<0.001$, the perception of woman; OR 12.78; IC [8.36 - 19.54] $\mathrm{P}<0,001$. The spouse's favorable opinion; OR 3.29; IC [2.23 - 4.96], $P<0.001$, the discussion with the spouse; OR 6.54; IC [3.86 - 11.07], $P<0.001$. the level of knowledge of MCM and the knowledge of the existence of FP services; OR 11,38; IC [5.56 - 23.30], $P<0.001$ et 8.75 [4.41 17.35], $P<0.001$.as regards modern contraceptive methods appeared as factors associated with the use of MCM after multivariate analysis (Table 3).

\section{Discussion}

The average age of the WCBA involved in our study was $29 \pm 5.6$ years old with extremes of 15 and 46 years old. This result is similar to those of Olamijulo et al.

Table 1. Distribution of WCBA surveyed according to the use of MCM and their type (Parakou 2017; $\mathrm{N}=1140$ ).

\begin{tabular}{ccc}
\hline & Number & Proportion in \% \\
\hline Use of MCM & 168 & 14.74 \\
Yes & 972 & 85.26 \\
No & & \\
Type of MCM & 17 & 10.12 \\
Oral Contraceptive & 72 & 42.86 \\
Injectable Contraceptive & 4 & 2.38 \\
IUD & 1 & 0.6 \\
Spermicide & 49 & 29.17 \\
Condom & 28 & 16.67 \\
Implant & 0 & 0 \\
Diaphragm and cervical cap & 1 & 0.6 \\
Femidom & 0 & 0 \\
Tubal Sterilization & 0 & 0 \\
Vasectomy &
\end{tabular}


Table 2. Distribution of WCBA surveyed according to their level of knowledge of MCM (Parakou 2017; N = 1140).

\begin{tabular}{ccc}
\hline & Number & Proportion in \% \\
\hline Knowledge & 72 & 6.31 \\
Poor & 155 & 13.6 \\
Insufficient & 651 & 57.11 \\
Average & 262 & 22.98 \\
Good & & \\
Heard of FP & 1068 & 93.68 \\
Yes & 72 & 6.32 \\
No & 191 & \\
& 797 & 17.88 \\
Care giver & 810 & 74.63 \\
Parents/Friends & 32 & 75.84 \\
Media & 120 & 3 \\
Association & 8 & 11.24 \\
School/University & & 0.75 \\
Internet & &
\end{tabular}

Table 3. Multivariate analysis of factors associated with the use of MCM (Parakou 2017; $\mathrm{N}=1140$ ).

\begin{tabular}{|c|c|c|c|}
\hline & OR & CI95\% & $P$-Value \\
\hline Age $(\leq 15 / \geq 40)$ & 1.09 & $0-1.12$ & 0.96 \\
\hline $\begin{array}{l}\text { Ethnic group } \\
\text { (Fonand related/Dendi) }\end{array}$ & 0.7 & $0.66-0.83$ & 0.99 \\
\hline $\begin{array}{l}\text { Maritus status } \\
\text { (Single/Married) }\end{array}$ & 0.7 & $0.61-0.87$ & 0.41 \\
\hline Religion (Christianity/Endogenous) & 1.4 & $0.15-14.49$ & 0.73 \\
\hline $\begin{array}{l}\text { Socioprofessional group [Civil servant/ } \\
\text { worker(blue collar)] }\end{array}$ & 0.9 & $0.89-1.08$ & 0.72 \\
\hline Educational level (Higher/Non educated) & 6.4 & $3.52-11.63$ & $P<0.001$ \\
\hline Socioeconomic level (High/low) & 0,7 & $0-1,12$ & 0.85 \\
\hline $\begin{array}{c}\text { Type of household } \\
\text { (No household / Monogamous) }\end{array}$ & 1,2 & $1.03-1.52$ & 0.13 \\
\hline $\begin{array}{c}\text { Parity } \\
\text { (Pauciparous/Nulliparous) }\end{array}$ & 0.8 & $0.73-0.96$ & 0.18 \\
\hline Heard of MCM (yes/no) & 1.04 & $0.01-1.12$ & 0.96 \\
\hline $\begin{array}{l}\text { Level of knowledge } \\
\text { (Good/insufficient) }\end{array}$ & 11.38 & $5.56-23.30$ & $P<0.001$ \\
\hline Perception of woman (good/bad) & 12.78 & $8.36-19.54$ & $P<0.001$ \\
\hline $\begin{array}{l}\text { Spouse's favorable opinion } \\
\text { (yes/bad) }\end{array}$ & 3.29 & $2.23-4.96$ & $P<0.001$ \\
\hline Discussion with the spouse(often/never) & 6.54 & $3.86-11.07$ & $P<0.001$ \\
\hline $\begin{array}{l}\text { Knowledge of the existence of FP services } \\
\text { (yes/no) }\end{array}$ & 8.75 & $4.41-17.35$ & $P<0.001$ \\
\hline
\end{tabular}


in Nigeria in 2012 and Traoré in Mali in 2008 in their studies carried out on populations. They had respectively found average ages of $30.86 \pm 7.54$ years old, 29.9 years old and $28 \pm 7.8$ years old [6] [7]. The average age of the respondents was similar to what some authors report in Africa [1] [8] [9].

In our study, the modern contraceptive prevalence was $14.74 \%$ as against $19 \%$ in Senegal and 11\% in Nigeria [8] [10]. This contraceptive prevalence in Parakou is currently within the limits of average prevalence in West Africa and has increased compared with the national average in 2006 which was $6 \%$ [1]. The strategic support given by technical and financial partners in the form of performance-based incentive has helped to improve this prevalence which varies according to methods. Injectable contraceptives were the most used as in Mali (52\%) in 2010 and in Senegal (55.6\%) in 2012 [7] [8]. This preference for injectable contraception is indicative of a context in which are associated the spouse's refusal, stigmatization of users, guarantee of confidentiality, very little constraint for the user and absence of the risk of oblivion. This level of utilization of modern contraception in Parakou could be improved if there are no limiting factors such as the fear of side effects, the spouses' unfavorable opinion, the desire to have a child and the ignorance of methods. The same factors were identified as determinants of the use of modern contraceptive methods in Africa and the world [7] [8] [9] [10]. So, 91\% and 70\% of good knowledge were reported in MBACKE's series in Senegal and Matungulu's ones in Congo [8] [9] against average knowledge of $62.8 \%$ in our series. The various awareness strategies and methods of knowledge assessment could account for these differences in the level of knowledge with regard to our results. Furthermore, the low educational level of the WCBA surveyed can be the reason for the poor knowledge of these women. In most cases, the level of knowledge was statistically in connection with the use of MCM in literature [9] [10] [11]. Thus, it seems necessary to improve the level of knowledge of these women by strengthening awareness campaigns directed to users who would become reliable and effective channels for a better promotion of modern contraception within communities. To reach the targets better, it is important to associate proximity campaigns performed by well-trained community links with mass campaigns devolved to the media in national languages without neglecting counseling which should precede the choice of a method. Similarly, the integrated practice of family planning services with other health services increases the chance to receive information about contraception [9]. Moreover, there was a significant statistical link between the perception and the attitude of WCBA with regard to MCM in our study as in those of Alemayehu in Ethiopia in 2012 [12] and Hotchkiss in Kenya in 2013 [13].

So, the perception of MCM by the women surveyed was bad in $50 \%$ of cases ; similar results to those of MBACKE in Senegal [9] and Ouattarain Côte d'Ivoire in 2012 [14] who had reported that the majority of women perceived MCM as a bad thing. This bad perception determined their attitude to MCM whose consequence was their low use [9] [15]. The very foundation of this low use remains 
the unfavorable opinion of the spouse for $25 \%$ of partners whose spouse took that into account in $72.72 \%$ of cases. Moreover, these women had no discussion with their spouse about MCM in $34.39 \%$ of cases. But, it is found in literature that women's discussions with their spouse was linked to the use of MCM [15]. Matungulu et al. in Congo in 2015 had observed that women who seldom or often had discussions with their partners, were respectively six and three times more likely inclined to use MCM than those who never had discussions [13]. In Ghana, Oheneba-Sakyi in 2014 had shown that women who used MCM were those who discussed family planning with spouses in favor of planning [15]. The same observation was made in several African countries [16] [17] [18] [19]. It is therefore essential to have discussions within couples to convince partners of the usefulness of MCM or at least incite them to participate in the various awareness campaigns about the issue. It seems crucial in our African societies where men still have the decision-making power totally. To achieve this end, it is important to develop and implement a communication strategy integrating men and women through services which provide family planning supplies. The fear of side effects was an obstacle to the use of MCM in this study as mentioned in a study carried out in the east of the Democratic Republic of Congo [20]. Insufficient counseling in family planning during consultations leads to rumors about these side effects which are increased and misrepresented and thus, reducing the adherence of WCBA to MCM. This issue must be taken into consideration by healthcare providers during healthcare provision related to family planning.

\section{Study Limitations}

The scope of the study was limited to the factors associated with the use of MCAs by women of childbearing age in the city of Parakou and not contraception in general; what we recommend for future research. This study could, however, include an information bias because of the method of questioning the women surveyed which is the one to one interview with the interviewers. Indeed, because of the sensitivity of the subject, there may be women who have not answered the question frankly. However, their number would be limited because of the explanations provided to the respondents before the start of the interview

\section{Conclusions}

The level of utilization still remains low. Any effort to increase modern contraceptive prevalence should take into account the educational level, the perception of woman, the spouse's favorable opinion, the discussion with the spouse, the level of knowledge of FP services in order to optimize the use of MCM in the municipality of Parakou in Benin.In order to mitigate the effects of its disadvantages on the use of CMC by women of childbearing age in the city of Parakou, it is necessary to:

1) Strengthen sex education and reproductive health programs in schools (middle and high schools), 
2) Encourage family planning programming through the media,

3) Intensify the promotion of family planning during pre-natal, post-natal and pre-school counseling.

4) Create and train community relays in family planning in women's and men's groups

5) Promote communication within the couple.

\section{References}

[1] (2011) Ministère du Développement de l'Analyse Economique et de la Prospective, INSAE. Demographic and Health Survey (EDSB-VI). 4th Edition.

[2] OMS and USAID (2008) Repositioning Family Planning. Geneva: Guidelines for Advocacy Actions.

http://www.who.int/reproductive-health/family_planning/index.html

[3] Gribblet, J. and Haffey, J. (2018) Factsheet on Reproductive Health in Sub-Saharan Africa. www.prb.org/francais

[4] Saifuddin, A., Li, Q.F., Li, L. and Amy, T. (2012) Maternal Deaths Averted by Contraceptive Use: An Analysis of 172 Countries. The Lancet, 380, 111-125.

[5] Essi, M.J. and Njoya, O. (2013) KAP Survey in Medical Research. The Journal of Medicine en Health Sciences, 14, 20-22.

www.hsd-fmsb.org/index.php/hsd/article/view/183

[6] Olamijulo, J. and Olorufemi, G. (2012) Knowledge and Practice of Contraception among Pregnant Women Attending the Antenatal Clinic in Lagos. Nigerian Journal of Medicine, 21, 387-393.

[7] Traore, A. (2010) Determinants of the Use of Family Planning Services by Women of Childbearing Age in Health Centers in Commune VI, Bamako District [Thèse de Med]. Université de Bamako.

[8] Mbacke Leye, M.-M., Faye, A. and Diongue, M. (2012) Determinants of the Use of Modern Contraception in the Health District of Mbacké (Senegal). Santépublique, 1, 1107-1116

[9] Matungulu, C., Kandolo, S., Mukengeshayi, A., Nkola, A. and Mpoyi, D. (2015) Determinants of Contraceptive Use in the Mumbunda Health Zone in Lubumbashi, Democratic Republic of Congo. Pan African Medical Journal, 22, 329-331.

[10] Tobin-West, C.I., Maduka, O., Okpani, A.O.U., Okonand Emmanuel, B.I. and Ezedinach, N.U. (2016) Determinants of Modern Contraceptive Uptake among Women in Peri-Urban Communities of Port Harcourt City, Nigeria. British Journal of Medicine \& Medical Research, 17, 1-10. https://doi.org/10.9734/BJMMR/2016/27655

[11] Chae, S., Woog, V., Zinsou, C. and Wilson, M. (2015) Obstacles to Contraceptive Practice of Women in Benin. Guttmacher Institute, New York. http://www.guttmacher.org/pubs/IB-Benin-contraception-fr.html

[12] Alemayehu, M., Tefera, B. and Tizta, T. (2012) Factors Associated with Utilization of Long Acting and Permanent Contraceptive Methods among Married Women of Reproductive Age in Mekelle Town, Tigray Region, North Ethiopia. BMC Pregnancy Child Birth, 12, 6. https://doi.org/10.1186/1471-2393-12-6

[13] Matungulu, M.C., Ilunga, K.S., Ntambue, M.A., Musau Nkola, A., et al. (2015) Déterminants de l'utilisation des méthodes contraceptives dans la zone de santé Mumbunda à Lubumbashi, République Démocratique du Congo. Pan African 
Medical Journal, 22, 329. https://doi.org/10.11604/pamj.2015.22.329.6262

[14] Ouattara, A. Study of the Factors of Underutilization of the Services of Family Planning and Prevention of STI/HIV/AIDS by the Populations of the Health Districts of Boundoukou and Tanda in the Republic of Côte d'Ivoire.

[15] Oheneba-Sakyi, Y. (1992) Determinants of Current Contraceptive Use among Ghanaian Women at the Highest Risk of Pregnancy. Journal of Biosocial Science, 24, 463-475. https://doi.org/10.1017/S0021932000020022

[16] Olugbenga-Bello, A.I., Abodunrin, O.L. and Adeomi, A.A. (2011) Contraceptive Practices among Women in Rural Communities in Southwestern Nigeria. Global Journal of Medical Research, 11, 1.

[17] Lwelamira, J., Mnyamagola, G. and Msaki, M.M. (2012) Knowledge, Attitude and Practice (KAP) towards Modern Contraceptives among Married Women of Reproductive Age in Mpwapwa District, Central Tanzania. Current Research Journal of Social Sciences, 4, 235-245.

[18] Kamal, S.M. and Islam, M.A. (2010) Contraceptive Use: Socioeconomic Correlates and Method Choices in Rural Bangladesh. Asia Pacific Journal of Public Health, 22, 436-450. https://doi.org/10.1177/1010539510370780

[19] Mohammed, A., Woldeyohannes, D., Feleke, A. and Megabiaw, B. (2014) Determinants of Modern Contraceptive Utilization among Married Women of Reproductive Age Group in North Shoa Zone, Amhara Region, Ethiopia. Reproductive Health, 11, 13. https://doi.org/10.1186/1742-4755-11-13

[20] Mathe, J.K., Kasonia, K.K. and Maliro, A.K. (2011) Barriers to Adoption of Family Planning among Women in Eastern Democratic Republic of Congo. African Journal of Reproductive Health, 15, 69-77. 